CARRA Working Paper Series

Working Paper \#2015-08

\title{
When Race and Hispanic Origin Reporting are Discrepant Across Administrative Records and Third Party Sources: Exploring Methods to Assign Responses
}

\author{
Sharon R. Ennis \\ U.S. Census Bureau \\ Sonya R. Porter \\ U.S. Census Bureau \\ James M. Noon \\ U.S. Census Bureau \\ Ellen Zapata \\ U.S. Census Bureau \\ Center for Administrative Records Research and Applications \\ U.S. Census Bureau \\ Washington, D.C. 20233
}

Paper Issued: December 18, 2015

Disclaimer: This paper is released to inform interested parties of research and to encourage discussion.

The views expressed are those of the authors and not necessarily those of the U.S. Census Bureau. 


\title{
When Race and Hispanic Origin Reporting are Discrepant Across Administrative Records and Third Party Sources: Exploring Methods to Assign Responses
}

\author{
Sharon R. Ennis, U.S. Census Bureau \\ Sonya R. Porter, U.S. Census Bureau \\ James M. Noon, U.S. Census Bureau \\ Ellen Zapata, U.S. Census Bureau
}

\begin{abstract}
The U.S. Census Bureau is researching uses of administrative records and third party data in survey and decennial census operations. One potential use of administrative records is to utilize these data when race and Hispanic origin responses are missing. When federal and third party administrative records are compiled, race and Hispanic origin responses are not always the same for an individual across sources. We explore different methods to assign one race and one Hispanic response when these responses are discrepant. We also describe the characteristics of individuals with matching, non-matching, and missing race and Hispanic origin data by demographic, household, and contextual variables. We find that minorities, especially Hispanics, are more likely to have non-matching Hispanic origin and race responses in administrative records and third party data compared to the 2010 Census. Minority groups and individuals ages 0-17 are more likely to have missing race or Hispanic origin data in administrative records and third party data. Larger households tend to have more missing race data in administrative records and third party data than smaller households.
\end{abstract}

Key Words: Race, Hispanic Origin, Administrative Records, Record Linkage 


\section{INTRODUCTION}

The U.S. Census Bureau is researching uses of administrative records and third party data (ARTPD) in survey and decennial operations in order to reduce costs and respondent burden while preserving data quality. One potential application of administrative records is to utilize the data when race and Hispanic origin responses are missing.

Item nonresponse for race and Hispanic origin is relatively low in census data. However, when a respondent does not provide a race or Hispanic origin, the Census Bureau employs methods such as hot decks to impute a response. A hot deck is geographically based, where responses from a nearest neighbor are used to impute missing responses to people with similar characteristics. The underlying assumption of a nearest neighbor hot deck is that people who live near each other share similar characteristics; however, with increasing racial and ethnic diversity in the U.S., this is less likely to be true (Farber et al. 2005).

For the first time in the 2010 Census, information that people had previously provided in either Census 2000 or the 2001-2009 American Community Surveys (ACS) were used to impute missing race and Hispanic origin responses. Previous census responses were used in almost 40 percent of all 2010 Census imputed Hispanic origin responses and 30 percent of all imputed race responses (Rothhaas et al. 2012). We may be able to expand on this imputation method to include other federal and third party sources (Rastogi et al. 2014).

Race and Hispanic origin responses in ARTPD may be able to assist not only with item nonresponse but also housing unit nonresponse. The Census Bureau is researching ways in which ARTPD could be used in decennial census operations when households do not respond to initial contact attempts. The quality of race and Hispanic origin data, as well as other demographic and housing data, in ARTPD is of crucial importance to this research.

However, when ARTPD are compiled, race and Hispanic origin responses are not always the same for an individual across different sources. In this paper, we explore different methods used to assign a single race and Hispanic origin response from ARTPD and evaluate which methods result in the highest level of agreement between an ARTPD composite of race and Hispanic origin responses and 2010 Census responses. We also describe the characteristics of individuals whose race or Hispanic origin responses in ARTPD match or do not match 2010 Census data, or have missing race or Hispanic origin responses in ARTPD.

In the next sections of this paper, we provide background on previous research on race and Hispanic origin data in ARTPD. Then we discuss the data and methods used in our analysis and present the results from our study. We conclude with a summary of our findings and propose future research. 


\section{BACKGROUND}

\section{Census Bureau Research on the Quality of Race and Hispanic Origin in Administrative Records and Third Party Data}

In response to expanding interest in the use of administrative records to enhance a decennial census, the Census Bureau developed the Statistical Administrative Records System (StARS) in 1999. ${ }^{1}$ StARS 1999 was developed to support the Administrative Records Experiment which simulated Census 2000 counts with administrative records (Bye and Judson 2004; Farber and Leggieri 2002). This previous research found that StARS had a lower representation of minorities compared to Census 2000. One of the limitations of the StARS administrative data was the inconsistent collection of race and ethnicity data. In particular, the Numident, which provided the widest coverage of race and ethnicity for the population, included Hispanic as a race category and did not collect multiple race responses (Farber and Leggieri 2002). In contrast, census data, adhering to the 1997 Office of Management and Budget (OMB) race and ethnicity standards, collects race and Hispanic origin as separate questions and starting in 2000 allowed for multiple-race reporting. StARS also modeled race and Hispanic origin when this information was missing in StARS, which likely contributed to differences between Census 2000 and StARS race and Hispanic origin data.

In a more recent study, the "2010 Census Match Study,” Rastogi and O'Hara (2012) expanded on this research and evaluated the agreement of demographic responses in ARTPD compared to the 2010 Census. In addition to the administrative sources used in StARS, this study utilized thirteen additional federal and third party files. Rastogi and O'Hara (2012) found that non-Hispanics had higher agreement rates compared to Hispanics. Race response agreement varied by race group. The White alone, Black alone, and Asian alone populations had higher agreement rates compared to the Two or More Races, Native Hawaiian or Other Pacific Islander (NHPI) alone, American Indian or Alaska Native (AIAN) alone, and Some Other Race (SOR) alone populations. In a study that replicated the "2010 Census Match Study" using data from the 2010 ACS, Bhaskar et al. (2014) found results for race and Hispanic origin that were consistent with those found by Rastogi and O'Hara (2012).

The race and Hispanic origin agreement patterns observed by Rastogi and O’Hara (2012) and Bhaskar et al. (2014) are consistent with literature on racial and ethnic fluidity.

\section{Racial and Ethnic Fluidity}

One reason an individual's race or Hispanic origin in administrative records may not match their response in census data is racial and Hispanic origin fluidity. Individuals may change their identity and/or identification over time or in different situations and contexts (e.g., Doyle and Kao 2007; Harris and Sim 2002; Liebler et al. 2014). Race response change varies considerably

\footnotetext{
${ }^{1}$ StARS 1999 was built from seven administrative files - the Internal Revenue Service (IRS) Individual Income Returns, IRS Information Returns, Department of Housing and Urban Development (HUD) Tenant Rental Assistance Certification System (TRACS), the Selective Service System Registration System, Indian Health Service (IHS) file, the Center for Medicare and Medicaid Services (CMS) Medicare Enrollment Database (MEDB), and the Social Security Administration Numerical Identification File (Numident) (Farber and Leggieri 2002).
} 
by race group. Non-Hispanic Whites, Blacks, and Asians are usually consistent in their race responses; while race response change is more common among non-Hispanic AIAN, NHPI, and multiracial individuals (Bentley et al. 2003; del Pinal and Schmidley 2005; Doyle and Kao 2007; Liebler et al. 2014). Previous Census Bureau research from the 1990, 2000, and 2010 censuses shows that individuals are relatively consistent in their responses to the Hispanic origin question with three percent or less changing their answer between the census and its corresponding reinterview (Dusch and Meier 2012; Singer and Ennis 2003; U.S. Census Bureau 1993).

Prior research shows substantial racial fluidity among Hispanics relative to non-Hispanics (Brown et al. 2006; Dusch and Meier 2012; Liebler et al. 2014; Singer and Ennis 2003). One factor that may affect race reporting among Hispanics is that although the federal government defines race and ethnicity as separate concepts, many Hispanics view race and ethnicity as one concept and identify their race as "Hispanic.” When faced with the federal standard racial categories, people who view their race as Hispanic may 1) not answer the race question, 2) report Hispanic responses that are tabulated as SOR, or 3) report a category that they feel may not be the best fit for their racial identity. Another factor affecting Hispanic racial identification is differences in questionnaire design. Campbell and Rogalin (2006) conducted a study that compared responses from separate ethnicity and race questions to a combined ethnicity and race question for the same respondent. The authors found that most Hispanics who chose a race in the separate question identified as Hispanic only to the combined ethnicity and race question.

\section{Characteristics of People with Non-Matching and Missing Hispanic Origin and Race Responses}

Previous research on non-matching race and ethnicity data found that agreement varies by demographic and socioeconomic characteristics. Males (Fernandez et al. 2015; McAlpine et al. 2007) and younger individuals (Gomez et al. 2005; Liebler et al. 2014) are more likely to have non-matching responses compared to females and older individuals. Individuals living in more affluent neighborhoods (Fernandez et al. 2015), people who live in the West, and people who respond through an interviewer compared to those who respond through mail tend to have nonmatching race and Hispanic origin responses (Liebler et al. 2014). Household structure also has an impact on responses. Those living alone have more consistent responses than those living with others (Kressin et al. 2003).

Few studies look at the patterns of missing race and Hispanic origin data in administrative records. We provide a brief overview of studies that have evaluated these patterns, but the findings are largely based on Medicaid (Fernandez et al. 2015; McAlpine et al. 2007) or Veteran's data (Kressin et al. 2003) and may not apply to other ARTPD. Previous studies comparing survey data to administrative records found that White and younger individuals are more likely to have missing race responses (Kressin et al. 2003; McAlpine et al. 2007). However, Fernandez et al. (2015) found that individuals who are Hispanic, AIAN, and older are more likely to have missing race responses in Medicaid administrative records. Males and people living in neighborhoods with higher median household incomes also tend to have missing race responses in Medicaid data (Fernandez et al. 2015). Similar to patterns for missing race, minorities and people living in neighborhoods with higher median household incomes are more likely to have missing Hispanic origin responses in Medicaid data (Fernandez et al. 2015). 
However, in contrast to missing race findings, females are more likely to have missing Hispanic origin responses in Medicaid data compared to males (Fernandez et al. 2015).

\section{DATA AND METHODS}

We used federal, state, and third party files to build a race and Hispanic origin ARTPD composite. We used previous census records (Census 2000 and ACS data from 2001 to 2009), the Numident, HUD TRACS, HUD Public and Indian Housing Information Center (PIC), HUD Computerized Homes Underwriting Management System (CHUMS), MEDB, IHS, and Temporary Assistance for Needy Families (TANF) data in our race assignment methods as well as our regression analysis. We used these same files plus Texas Supplemental Nutrition Assistance Program data (SNAP), Medicaid Statistical Information System (MSIS), and third party files to assign Hispanic origin, as these additional sources indicated high levels of agreement for Hispanic origin responses but not race responses.

Administrative records sources vary in the collection of Hispanic origin and race data. Many of the federal files report race and ethnicity according to OMB's revised 1997 race and ethnic standards. ${ }^{2}$ However, there are a few exceptions. HUD TRACS collects an individual's ethnicity and race, but the 2010 HUD TRACS dataset used in this study has information for individuals for Hispanic origin or race, but not both. The Numident, MEDB, and Texas SNAP files treat race and Hispanic origin as one concept and have one combined race and ethnicity variable. In other words, the categories of the variable include "Hispanic" in addition to the race groups. Additionally, the Numident and MEDB data have a combined category for Asian and Pacific Islander and do not collect multiple responses or include a category for multiracial persons. ${ }^{3}$

In order to compare the race and ethnicity data from the Numident, MEDB, and Texas SNAP files to the 2010 Census, we recoded the combined race and ethnicity variable into two separate variables, one for ethnicity and one for race. Individuals who were identified as Hispanic were coded as such with missing race information since we have no information about their race. Similarly, individuals who were identified as a race were coded as that race group with missing Hispanic origin information. For example, if an individual identified as Black, then the separate ethnicity variable was coded as missing and the race variable was coded as "Black." If an individual was identified as the combined category Asian/Pacific Islander then their race was coded as missing since we cannot determine with which OMB racial category-Asian or NHPI—the individual identifies.

Although the HUD PIC, HUD CHUMS, and TANF files collect race and Hispanic origin according to the OMB standards, these files do not include a category for SOR, unlike census

\footnotetext{
${ }^{2}$ Federal agencies must adhere to race and ethnicity standards issued by the OMB. There are a minimum of two ethnicities: Hispanic or Latino and Not Hispanic or Latino. There are five categories on race: White, Black or African American, American Indian or Alaska Native, Asian, and Native Hawaiian or Other Pacific Islander. For respondents who do not identify with any of these five race categories, OMB approved the Census Bureau's inclusion of a sixth category, Some Other Race. Respondents are also permitted to identify with more than one race. The standards are available online at <www.whitehouse.gov/omb/fedreg/1997standards.html>.

${ }^{3}$ The Texas SNAP data also does not have a category for multiracial persons and has a combined Asian and Pacific Islander category. However, the Texas SNAP data is not used in assigning race to the ARTPD composite.
} 
data. $^{4}$ The IHS file only identifies individuals as either AIAN or non-AIAN. The third party files model race and Hispanic origin data using information on surname and geography.

We link the ARTPD race and Hispanic origin composite to 2010 Census data for our analyses. All person records were processed through the Person Identification Validation System (PVS), which used probability record linkage techniques (Fellegi and Sunter 1969) and personal information such as name and date of birth to assign an anonymized unique Protected Identification Key (PIK) to each person, as possible (see Wagner and Layne 2014). The method is least robust for people who do not have a Social Security Number and those whose personal information is ambiguous or incomplete. Once the PIK was assigned in each separate data set, it was used to link a person's record in the 2010 Census to his or her own record in the race and Hispanic origin ARTPD composite.

We use descriptive statistics to evaluate two methods to assign Hispanic origin from ARTPD and six methods to assign race. We evaluate the methods by matching Hispanic and race response results from each method to 2010 Census unedited race and Hispanic origin responses. Records without any available Hispanic origin or race data are not included in the descriptive match rates.

We chose one promising Hispanic origin assignment method and one promising race assignment method based on the descriptive statistics and applied multinomial regression analysis to understand the characteristics of those who have matching, non-matching, and missing race and Hispanic origin data. We perform multinomial regression analysis separately for Hispanic origin and for race. These models predict whether a linked Census-ARTPD record matches on Hispanic origin or race (coded as “ 0 ”), whether the Hispanic origin or race data do not match (coded as “1”), and whether the ARTPD record does not have any available Hispanic origin or race data (coded as “2”). Because the dependent variables include ARTPD records with missing demographic data, the distributions for the dependent variables differ from the distribution for matching Hispanic origin and race data presented in the descriptive analysis. As with the descriptive statistics, the models are limited to census records that are unedited.

The independent variables for the regressions include individual-level demographic variables, household-level characteristics, tract-level contextual characteristics, and region. Individual-level variables include the person's Hispanic origin, race, age, and gender as reported in the Census. We used a combined Hispanic origin and race independent variable with categories Hispanic, non-Hispanic White alone, non-Hispanic Black alone, etc. We excluded the non-Hispanic SOR and non-Hispanic multiracial groups from the regression analysis because not all ARTPD sources have an SOR category or collect multiple races. Household-level variables include household tenure, household type and size as reported in the Census, the Census mode in which the household responded, and whether the household lives in an urban or rural area. In addition, tract-level variables measure the percent of non-Hispanic Whites in the tract in the Census and the logged median household income in the tract according to ACS 2006-2010 5-year data.

\footnotetext{
${ }^{4}$ Also, the Texas SNAP and MSIS files do not contain an SOR category. These data are not used in assigning race to the ARTPD composite.
} 


\section{Limitations}

Our analysis does not include people in administrative records who were not assigned a PIK. The characteristics of individuals who receive a PIK are different from those who do not receive a PIK (Bond et al. 2014), which could bias our results. In addition, people in administrative records that did receive a PIK but could not be linked to 2010 Census data are not included in the analysis. This too is likely to result in some bias in our findings. Therefore, our results should be interpreted with caution.

\section{RESULTS}

We first discuss Hispanic origin and race assignment methods and which methods resulted in the highest match between ARTPD and 2010 Census data for race and Hispanic origin responses. Then, we discuss results from the multinomial regression analysis.

\section{Hispanic Origin and Race Assignment Methods}

We developed methods to assign Hispanic origin and race data to the ARTPD composite based on available information in the administrative records and third party files. Once we assign a Hispanic origin or race to a record, the response is not overwritten by responses from any other files.

\section{Hispanic Origin}

We considered two different methods in assigning a Hispanic origin response. Figure 1 illustrates how we applied these methods to assign one Hispanic origin response to the ARTPD composite. If there was no discrepancy in an individual's ethnicity response across source files then that response was assigned to the composite. This is shown in the first three rows of the figure. Of the 352 million records in the ARTPD composite, there were 278 million (79 percent) that had no discrepancy in Hispanic origin responses (see Table 1). Approximately 86 million (25 percent) had only one source of Hispanic origin data and 191 million (54 percent) records had the same Hispanic origin response across two or more sources.

There were 11 million (3 percent) individuals in the composite with discrepant ethnicity responses. When there are differences across the administrative records and third party source files, we assigned a Hispanic origin response according to the following:

In Method 1, a Hispanic response was assigned if a Hispanic response was present in any of the ARTPD sources. This is reflected in rows 4 and 5 in the "Method 1" column. ARTPD does not cover Hispanics as well as non-Hispanics and the agreement between ARTPD and census Hispanic responses is lower compared to non-Hispanics (Bhaskar et al. 2014; Luque and Bhaskar 2014; Rastogi and O’Hara 2012). Thus, in this method, we gave priority to Hispanic responses to maximize the coverage of Hispanic responses in the ARTPD composite.

In Method 2, if a Hispanic origin response was found in previous census records, then that Hispanic or non-Hispanic response was assigned to the composite. This is shown in row 4 of the 
"Method 2" column in Figure 1. Hispanic origin identification can be affected by questionnaire design (Campbell and Rogalin 2006). Therefore, in this method, we gave priority to previous census records since the format is the most similar to the 2010 Census, relative to ARTPD sources. If a response was missing in previous census records, then a Hispanic response was assigned if present in any other administrative records source. This is reflected in row 5.

As shown in the last row of the figure, if Hispanic origin information is missing, then the response is set to missing in the ARTPD composite. Table 1 shows that approximately 63 million (18 percent) individuals in the ARTPD composite had no Hispanic origin information.

Once a single Hispanic origin response was assigned to the ARTPD composite using each method, the composite was then linked to 2010 Census data, and match rates for response agreement were calculated to evaluate the quality of the Hispanic origin responses in ARTPD. The match rates for each method are shown in Table 2. The agreement rate for Hispanics in Method 1 is higher (94 percent) compared to Method 2 (92 percent), while the agreement rate for non-Hispanics is higher in Method 2 (99 percent) compared to Method 1 (97 percent). For this paper, we chose to further evaluate Method 1 using multinomial regressions since the agreement rate is higher for Hispanics compared to Method 2.

\section{Race}

We explored six different methods of assigning a single race response, and they are described below. Figure 2 shows how we applied the business rules described in each method to assign one race response from administrative records. If there is no discrepancy in an individual's race responses across files, then that race was assigned to the administrative records composite. This is reflected in the first two rows of Figure 2. As shown in Table 1, there were 274 million (78 percent) records in the composite with no discrepancy across race responses. About 91 million (26 percent) had only one source of race data, and 183 million (52 percent) had the same race response across multiple sources.

Approximately 9 million (3 percent) of individuals in the composite had different race responses. If responses across source files are discrepant, race was assigned in the following manner:

Methods 1 and 2 prioritized smaller race groups over larger ones, since smaller race groups experience lower race response agreement and greater coverage issues. A single race was assigned with preference given to smaller race groups according to their share of the total 2010 Census population distribution. As NHPI alone is the smallest of the seven race categories, it was selected first if it was in any of the source files, as demonstrated in rows 3 and 4 of the figure. Then race was selected in the following order - AIAN alone, Two or More Races, Asian alone, SOR alone, Black alone, and then White alone. Method 2 is similar to Method 1, but preference was given to Two or More Races first, followed by NHPI alone, AIAN alone, Asian alone, SOR alone, Black alone, and then White alone. This is demonstrated in row 3, in the "Method 2" column of Figure 2. We chose to prioritize Two or More Races first in this method because this group experiences lower agreement and coverage rates in ARTPD relative to other groups (Rastogi and O’Hara 2012). 
For Methods 3 and 4 we prioritized the race response that was most frequently reported across ARTPD. For Method 3, this is demonstrated in rows 3, 5, and 6 of the column labeled "Method 3" of Figure 2. If there was no most frequent race, then race was assigned with preference given to smaller race groups using the same order as in Method 1. This is demonstrated in row 4 of the figure. For Method 4, if there was no most frequent race, then race was assigned with preference given to the smaller race groups using the same order as in Method 2. This is demonstrated in row 7 of the figure.

In Methods 5 and 6, we evaluated whether dataset order impacted agreement rates. Since, previous census records are most similar in format and design to the 2010 Census, we assigned a race response to the ARTPD composite first from this data source. This is shown in rows 3, 5, 6 and 7 of the "Method 5" column. If a response was missing in previous census records, then a race response was assigned according to Method 1 . This is reflected in row 4. In Method 6, we evaluated whether using IHS before other datasets would increase agreement response rates for American Indians and Alaska Natives. This is illustrated in rows 4, 5, and 6. Otherwise, a race response was assigned as described in Method 5. Rows 3 and 7 of the "Method 6" column provide examples of this.

As with the Hispanic origin assignment, if there are no race responses in administrative records, then race is set to missing in the composite file regardless of the method used. This is illustrated in the last row of Figure 2. There were 69 million (20 percent) individuals in the composite with missing race information (see Table 1 ).

The match rates for each race method are shown in Table 3. Method 1 generally looks like the best method. Method 1 has the highest agreement rates for AIAN and NHPI and very similar agreement rates for single race Whites, Blacks, and those who report SOR alone compared to other methods. The agreement rate for Asians is very similar to some of the other methods; Methods 3 and 4 have much lower agreement rates for Asians compared to the other methods (86 percent compared to 91 percent, respectively). The agreement rate for Two or More Races is also quite similar across the methods, but Methods 2 and 5 have slightly higher agreement rates (30 percent) compared to Method 1 (29 percent).

\section{Nonresponse Follow-up Universe}

ARTPD race and Hispanic origin data may be used in the 2020 Census in nonresponse follow-up operations when these data are missing. ${ }^{5}$ We calculated the 2010 Census-ARTPD agreement rates for each method (shown in Table 4 for Hispanic origin and Table 5 for race). Hispanic Method 1 and Race Method 1 resulted in the highest agreement rates for Hispanics and the smaller race groups in the nonresponse follow-up universe. The agreement rates for Hispanics and non-Hispanics were 92 percent and 96 percent, respectively. The agreement rates for race are slightly lower in the nonresponse follow-up universe compared to the 2010 Census results, ranging from 21 percent for Two or More Races to 96 percent for Black alone.

\footnotetext{
${ }^{5}$ During the nonresponse follow-up operations, households that do not respond by mail or internet to the decennial census receive a personal visit from an enumerator in order to collect the household's census information.
} 


\section{Regression Results}

Next, using multinomial regressions, we discuss factors associated with matching, non-matching, and missing Hispanic origin (model 1) and race (model 2) responses between the 2010 Census and ARTPD. Table 6 presents the distribution of the dependent variables. Overall, about 87 percent of individuals have matching Hispanic origin responses, 3 percent have non-matching or different Hispanic origin responses, and 10 percent have missing Hispanic origin data in ARTPD. A smaller percentage of respondents have matching race responses at 78 percent. Five percent of respondents have different race responses between the two data sources and 17 percent are missing race data in administrative records.

Model 1 shows that Hispanics are more likely to have non-matching Hispanic origin responses but less likely to have missing Hispanic origin data in ARTPD compared to non-Hispanic Whites (Table 7). In model 2, we see that Hispanics are 43 times more likely to have non-matching race responses in ARTPD than non-Hispanic Whites. Also, the odds of having missing race responses are about 11 times larger for Hispanics than non-Hispanic Whites. One factor contributing to these results is that many Hispanics view their race as "Hispanic" and do not identify with OMB's standard race groups.

With the exception of non-Hispanic Black individuals in the Hispanic origin model, nonHispanic minorities are significantly more likely to have different Hispanic origin and race responses in ARTPD than in the Census compared to non-Hispanic Whites. In fact, the odds of having non-matching race responses are 14 and 36 times larger for non-Hispanic AIAN and nonHispanic NHPI individuals, respectively, relative to non-Hispanic Whites. This is consistent with previous research that shows that response change is more common in AIAN and NHPI groups (Bentley et al. 2003; del Pinal and Schmidley 2005; Liebler et al. 2014). The coefficients in both models show that race and Hispanic origin data in ARTPD is more likely to be missing for nonHispanic Asians and non-Hispanic NHPIs than for non-Hispanic Whites.

There are differences in matching race and Hispanic origin by age and gender. Individuals aged 45 and older are more likely to have the same race and Hispanic origin responses in the Census and ARTPD, however, individuals aged 17 and younger are less likely to have matching responses than those aged 18 to 44 years. This pattern is consistent with previous studies measuring agreement of race and Hispanic origin data in surveys and administrative records (Gomez et al. 2005; McAlpine et al. 2007). Younger individuals are 17 and 13 times more likely to have missing race and Hispanic origin administrative records data, respectively. These results are consistent with findings from previous research that coverage in administrative records is lower for younger age groups compared to older age groups (Farber and Leggieri 2002; Rastogi and O'Hara 2012). Males are less likely to have non-matching Hispanic origin responses. This contradicts earlier research that finds that males have a lower likelihood of having consistent ethnicity responses than females (Fernandez et al. 2015; McAlpine et al. 2007). Consistent with prior research using administrative records data, males are more likely to have non-matching race responses than females (Fernandez et al. 2015; McAlpine et al. 2007). In addition, males are more likely to have missing Hispanic origin data. 
Compared to individuals who responded to the 2010 Census by mail, individuals who responded to the Census in the nonresponse follow-up operation or other modes are more likely to have non-matching race and Hispanic origin responses in ARTPD. The presence of an enumerator in the 2010 Census nonresponse follow-up operation may affect a respondent's response to the Hispanic origin and race questions. In a study of Hispanic origin and race response change between Census 2000 and the 2010 Census, Liebler et al. (2014) found that response change is common among people who responded to one or both censuses using a response mode other than mail. Responding to the Census by non-mail modes is associated with a greater likelihood of missing race and Hispanic origin data in ARTPD.

Race and Hispanic origin response agreement between the 2010 Census and ARTPD varies by geography. Consistent with findings from earlier research, residents living in the West are more likely to have non-matching Hispanic origin and race responses than those residing in the Midwest, South, or Northeast (Liebler et al. 2014). Individuals living in regions other than the West are less likely to have missing Hispanic origin responses but more likely to have missing race data. In addition, living in rural areas is associated with matching responses for both race and Hispanic origin. Minority groups are more likely to have non-matching race responses compared to Whites (Liebler et al. 2014) and are also more likely to live in urban areas (U.S. Census Bureau 2010), which may in part be why we observe more matching responses in rural areas.

In terms of household characteristics, renters, households headed by single parents or that have other household compositions, and individuals living in households with two or more people are more likely to have different Hispanic origin and race responses compared to homeowners, households headed by married couples, and individuals who live alone. Households headed by single parents are less likely to have missing race and Hispanic origin data than households headed by married couples. Renters and individuals living in households with two or more people are more likely to have missing race and Hispanic origin data in ARTPD than homeowners and single person households.

As the median household income in the tract of residence increases, the odds of having a nonmatching or missing Hispanic origin response in ARTPD increase. Individuals living in more affluent neighborhoods are more likely to have missing race data than those in neighborhoods with lower median household incomes. These findings are consistent with the work of Fernandez et al. (2015).

\section{Nonresponse Follow-up Universe}

We ran multinomial regressions on the nonresponse follow-up universe. Table 8 shows the distribution of the dependent variables in the nonresponse follow-up universe. In comparison to the total universe, the percentage of individuals having matching Hispanic origin responses is lower in the nonresponse follow-up universe at 84 percent. A larger percentage of respondents have non-matching and missing ARTPD Hispanic origin responses in the nonresponse follow-up universe at 4 percent and 12 percent, respectively. Similar to the results for Hispanic origin, a smaller percentage of respondents have matching race responses and a larger percentage have non-matching and missing ARTPD race responses in the nonresponse follow-up universe than in 
the total universe. About 71 percent of individuals have matching race responses in the 2010 Census NRFU and ARTPD data, 7 percent have different race responses, and 22 percent have missing race data in ARTPD.

The regression results in the nonresponse follow-up universe are generally similar to those in the total universe (Table 9). Specifically, the patterns are similar for all of the demographic variables; however, there are some minor differences in the results for the household and contextual variables.

\section{CONCLUSION}

In this research, we explored different methods for assigning one race and Hispanic origin response when responses are discrepant across ARTPD sources. We evaluated which methods resulted in the highest level of agreement with the 2010 Census and find that Hispanic Method 1 and Race Method 1 resulted in the highest match rates for Hispanics and smaller race groups, respectively. For Hispanic origin, the match rate was 94 percent for Hispanics and 97 percent for non-Hispanics. The most successful method in assigning race resulted in match rates ranging from 29 percent for Two or More Races to 96 percent for White alone and Black alone. Match rates were higher for single race Whites, Blacks, and Asians and lower rates for single race AIANs, NHPIs, those who report SOR, and Two or More Races.

We also described the characteristics of individuals whose Hispanic origin and race responses in ARTPD do not match 2010 Census data or are missing. We find that many demographic, household, and contextual variables are associated with non-matching and missing race and Hispanic origin responses. The magnitude of race, ethnicity, age, and household size odds ratios are notable.

We find that minorities, especially Hispanics, are more likely to have non-matching Hispanic origin and race responses in ARTPD compared to the 2010 Census. These results are consistent with those found in other studies on racial and ethnic fluidity. Hispanics are less likely to have missing Hispanic origin data but more likely to have missing race data in ARTPD. Hispanics' higher likelihood of missing race data in ARTPD relative to non-Hispanic Whites may be in part due to not identifying with the response options offered. We also find that non-Hispanic Asian and NHPI individuals are more likely to have missing race and Hispanic origin data in ARTPD.

Consistent with previous research that children are not covered as well as adults in ARTPD (Bhaskar et al. 2014; Rastogi and O’Hara 2012), individuals ages 0-17 are more likely to have missing race and Hispanic origin responses. Household size is also strongly associated with missing race data, where larger households tend to have missing race data compared to smaller households. This may also be related to coverage of children issues in ARTPD.

Our findings suggest that using ARTPD when race and Hispanic origin responses are missing is a promising approach. The quality of ARTPD is high for the White alone, Black alone, and Asian alone populations, and these data can assist in assigning responses when data are missing. Our results concur with those found during Census 2000 research and show that ARTPD race and Hispanic origin responses for minority groups had lower levels of agreement with 2010 
Census data relative to non-Hispanic Whites. Although the quality of race and Hispanic origin administrative data appears to be lower for some minority groups, our results are consistent with earlier research on racial and ethnic fluidity.

As the Census Bureau acquires more administrative records and third party data sources, we will evaluate the agreement of Hispanic origin and race response data relative to census data in order to assess the use of these sources in the ARTPD race and Hispanic origin composite. We are currently in the process of acquiring SNAP and Women, Infants, and Children program data from states and will evaluate these data for the ARTPD composite. We will also explore additional methods to assign race and Hispanic origin from ARTPD.

By developing methods to assign one Hispanic origin and race response when these responses are discrepant across administrative records sources, our research can inform imputation strategies to address race and ethnicity item nonresponse in census surveys and the 2020 Census. Our research can also inform other Census Bureau programs including the Population Estimates Program where national population estimates by race and ethnicity are developed using administrative records. By contributing to a better understanding of the factors associated with non-matching and missing race and Hispanic origin data in ARTPD, our analysis will inform the application of ARTPD race and Hispanic origin data to Census operations and research as well as research on race and Hispanic origin reporting, measurement, and fluidity. 


\section{REFERENCES}

Bentley, Michael, Tracy Mattingly, Christine Hough, and Claudette Bennett. 2003. “Census Quality Survey to Evaluate Responses to the Census 2000 Question on Race: An Introduction to the Data.” Census 2000 Evaluation B.3. Washington, DC: U.S. Census Bureau.

Bhaskar, Renuka, Adela Luque, Sonya Rastogi, and James Noon. 2014. “Coverage and Agreement of Administrative Records and 2010 American Community Survey Demographic Data.” Center for Administrative Records Research and Applications Working Paper \#2014-14. Washington, DC: U.S. Census Bureau.

Bond, Brittany, J. David Brown, Adela Luque, and Amy O’Hara. 2014. “The Nature of the Bias When Studying Only Linkable Person Records: Evidence from the American Community Survey." Center for Administrative Records Research and Applications Working Paper \#201408. Washington, DC: U.S. Census Bureau.

Brown, J. Scott, Steven Hitlin, and Glen H. Elder, Jr. 2006. “The Greater Complexity of Lived Race: An Extension of Harris and Sim.” Social Science Quarterly 87(2): 411-431.

Bye, Barry and Dean Judson. 2004. "Results From the Administrative Records Experiment in 2000.” Census 2000 Synthesis Report No. 16. Washington, DC: U.S. Census Bureau.

Campbell, Mary E. and Christabel L. Rogalin. 2006. “Categorical Imperatives: The Interaction of Latino and Racial Identification.” Social Science Quarterly 87(5):1030-1052.

del Pinal, Jorge and Dianne Schmidley. 2005. "Matched Race and Hispanic Origin Responses from Census 2000 and Current Population Survey February to May 2000.” Population Division Working Paper No. 79. Washington, DC: U.S. Census Bureau.

Doyle, Jamie M. and Grace Kao. 2007. “Are Racial Identities of Multiracials Stable? Changing Self-Identification among Single and Multiple Race Individuals.” Social Psychology Quarterly 70(4):405-423.

Dusch, Gianna and Fred Meier. 2012. “2010 Census Content Reinterview Survey Evaluation Report.” 2010 Census Program for Evaluations and Experiments. Washington, DC: U.S. Census Bureau.

Farber, James and Charlene Leggieri. 2002. "Building and Validating a National Administrative Records Database for the United States.” New Zealand Conference on Database Integration.

Farber, James, Deborah Wagner, and Dean Resnick. 2005. "Using Administrative Records for Imputation in the Decennial Census.” Proceedings of the 2005 Joint Statistical Meetings, Survey Research Methods Section, Alexandria, VA: American Statistical Association. 
Fellegi, Ivan P. and Alan. B. Sunter. 1969. “A Theory for Record Linkage.” Journal of the American Statistical Association, 64, 1183-1210.

Fernandez, Leticia, Sonya Rastogi, Sharon R. Ennis, and James Noon. 2015. "Evaluating Race and Hispanic Origin Responses of Medicaid Participants Using Census Data." Center for Administrative Records Research and Applications Working Paper \#2015-01. Washington, DC: U.S. Census Bureau.

Gomez, Scarlett L., Jennifer L. Kelsey, Sally L. Glaser, Marion M. Lee, and Stephen Sidney. 2005. "Inconsistencies between Self-Reported Ethnicity and Ethnicity Recorded in a Health Maintenance Organization.” Ann Epidemiol 15(1): 71-79.

Harris, David and Jeremiah Joseph Sim. 2002. "Who is Multiracial? Assessing the Complexity of Lived Race.” American Sociological Review 67(4): 614-627.

Kressin, Nancy R., Bei-Hung Chang, Ann Hendricks, and Lewis E. Kazis. 2003. "Agreement between Administrative Data and Patients' Self-Reports of Race/Ethnicity.” American Journal of Public Health 93(10): 1734-1739.

Liebler, Carolyn A., Sonya Rastogi, Leticia E. Fernandez, James Noon, and Sharon R. Ennis. 2014. "America's Churning Races: Race and Ethnic Response Changes between Census 2000 and the 2010 Census." Center for Administrative Records Research and Applications Working Paper \#2014-03. Washington, DC: U.S. Census Bureau.

Luque, Adela and Renuka Bhaskar. 2014. "2010 American Community Survey Match Study.” Center for Administrative Records Research and Applications Working Paper \#2014-03. Washington, DC: U.S. Census Bureau.

McAlpine, Donna D., Timothy J. Beebe, Michael Davern, and Kathleen T. Call. 2007. "Agreement between Self-Reported and Administrative Race and Ethnicity Data among Medicaid Enrollees in Minnesota.” Health Services Research 42(6): 2373-2388.

Rastogi, Sonya, Leticia Fernandez, James Noon, Ellen Zapata, and Renuka Bhaskar. 2014. "Exploring Administrative Records Use for Race and Hispanic Origin Item Non-Response." Center for Administrative Records Research and Applications Working Paper \#2014-16. Washington, DC: U.S. Census Bureau.

Rastogi, Sonya and Amy O'Hara. 2012. "2010 Census Match Study.” 2010 Census Planning Memoranda Series \#247. Washington, DC: U.S. Census Bureau.

Rothhaas, Cynthia, Frederic Lestina, and Joan M. Hill. 2012. "2010 Census Item Nonresponse and Imputation Assessment Report.” 2010 Census Planning Memoranda Series \#173, U.S. Washington, DC: U.S. Census Bureau. 
Singer, Phyllis and Sharon R. Ennis. 2003. "Census 2000 Content Reinterview Survey: Accuracy of Data for Selected Population and Housing Characteristics as Measured by Reinterview.” Census 2000 Evaluation B.5.Washington, DC: U.S. Census Bureau.

U.S. Census Bureau. 2010. 2010 Census Summary File 1; Table P5; generated by Sharon Ennis; using American FactFinder; <http://factfinder2.census.gov>; (16 January 2015).

U.S. Census Bureau. 1993. “Content Reinterview Survey: Accuracy of Data for Selected Population and Housing Characteristics as Measured by Reinterview.” 1990 Census of Population and Housing Evaluation and Research Reports. Washington, DC: U.S. Census Bureau.

Wagner, Deborah and Mary Layne. 2014. “The Person Identification Validation System (PVS): Applying the Center for Administrative Records Research \& Applications Record Linkage Software.” Center for Administrative Records Research and Applications Working Paper \#201401. Washington, DC: U.S. Census Bureau. 


\section{Acknowledgements}

The authors would like to thank Leticia E. Fernandez and Amy O'Hara for their helpful comments and suggestions. 


\begin{tabular}{|lllllll|}
\hline \multicolumn{6}{|l}{ Figure 1. Methods used to Assign Hispanic Origin Response to the ARTPD Composite } \\
Example \# & ARTPD & Source 1 & ARTPD & ARTPD & & \\
& Source 2 & Source 3 & Previous Census & Method 1 & Method 2 \\
2 & Non-Hispanic & Non-Hispanic & Non-Hispanic & Non-Hispanic & Non-Hispanic & Non-Hispanic \\
3 & Missing & Non-Hispanic & Missing & Missing & Non-Hispanic & Non-Hispanic \\
4 & Hispanic & Hispanic & Missing & Hispanic & Hispanic & Hispanic \\
5 & Hispanic & Hispanic & Missing & Non-Hispanic & Hispanic & Non-Hispanic \\
6 & Non-Hispanic & Non-Hispanic & Hispanic & Missing & Hispanic & Hispanic \\
\hline Missing & Missing & Missing & Missing & Missing & Missing \\
\hline
\end{tabular}

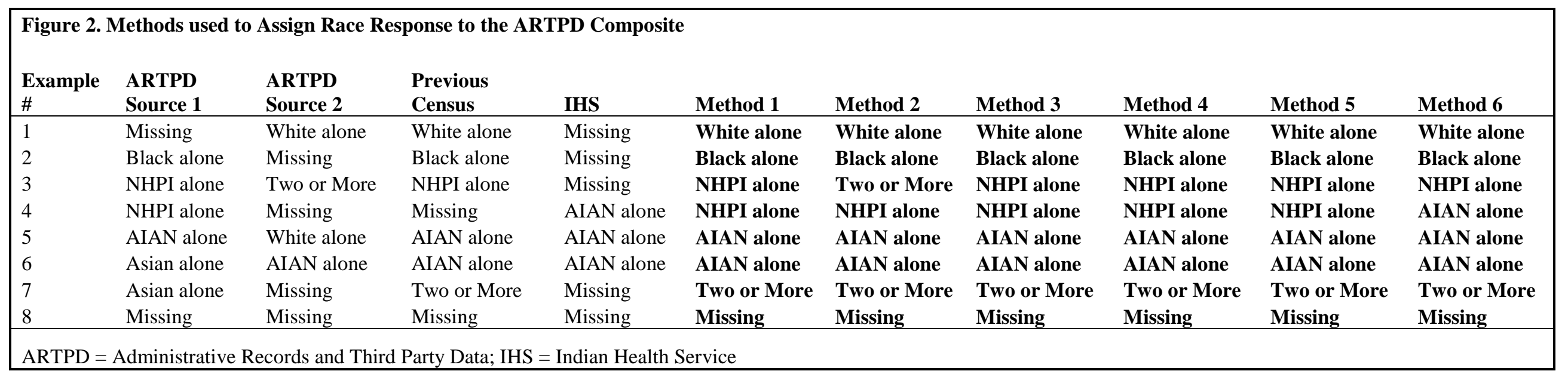


Table 1. Percentage of Records in the ARTPD Composite with a Discrepancy Across Source Files or Missing Data

\begin{tabular}{l|cr|rr|} 
& \multicolumn{2}{|c|}{ Hispanic Origin } & \multicolumn{2}{c|}{ Race } \\
& Number & Percent & \multicolumn{1}{c|}{ Number } & Percent \\
\hline Total records & $351,618,175$ & 100.0 & $351,618,175$ & 100.0 \\
No discrepancy across source files & & & & \\
One source with data & $277,723,876$ & 79.0 & $273,759,382$ & 77.9 \\
Two or more sources with data & $86,447,226$ & 24.6 & $90,743,297$ & 25.8 \\
Discrepancy across source files & $191,276,650$ & 54.4 & $183,016,085$ & 52.0 \\
Missing data & $11,378,349$ & 3.2 & $9,091,536$ & 2.6 \\
Source: Administrative Records and Third Party Data & $62,515,950$ & 17.8 & $68,767,257$ & 19.6 \\
Note: ARTPD = Administrative Records and Third Party Data \\
\hline
\end{tabular}

Table 2. Percentage of ARTPD Hispanic Origin Data Matched to the 2010 Census

\begin{tabular}{|c|c|c|c|c|}
\hline \multirow{2}{*}{$\begin{array}{l}\text { Hispanic Origin } \\
\text { Responses }\end{array}$} & \multicolumn{2}{|c|}{ Method 1} & \multicolumn{2}{|c|}{ Method 2} \\
\hline & Number & Percent & Number & Percent \\
\hline Hispanic & $30,253,046$ & 93.7 & $29,713,244$ & 92.0 \\
\hline Non-Hispanic & $191,087,892$ & 96.8 & $195,097,141$ & 98.8 \\
\hline
\end{tabular}

Source: 2010 Census and ARTPD

Note: ARTPD = Administrative Records and Third Party Data 
Table 3. Percentage of ARTPD Race Data Matched to the 2010 Census

\begin{tabular}{|c|c|c|c|c|c|c|c|c|c|c|c|c|}
\hline \multirow{2}{*}{$\begin{array}{l}\text { Race } \\
\text { Responses }\end{array}$} & \multicolumn{2}{|c|}{ Method 1} & \multicolumn{2}{|c|}{ Method 2} & \multicolumn{2}{|c|}{ Method 3} & \multicolumn{2}{|c|}{ Method 4} & \multicolumn{2}{|c|}{ Method 5} & \multicolumn{2}{|c|}{ Method 6} \\
\hline & Number & Percent & Number & Percent & Number & Percent & Number & Percent & Number & Percent & Number & Percent \\
\hline White alone & $161,093,312$ & 96.5 & $161,093,312$ & 96.5 & $161,748,097$ & 96.9 & $161,748,097$ & 96.9 & $161,817,315$ & 96.9 & $161,745,421$ & 96.9 \\
\hline Black alone & $26,660,073$ & 96.4 & $26,660,073$ & 96.4 & $26,776,690$ & 96.8 & $26,776,690$ & 96.8 & $26,706,261$ & 96.6 & 26,702,739 & 96.6 \\
\hline AIAN alone & $1,494,452$ & 74.3 & $1,414,241$ & 70.3 & $1,430,924$ & 71.1 & $1,385,324$ & 68.9 & $1,357,520$ & 67.5 & $1,466,302$ & 72.9 \\
\hline Asian alone & $6,598,137$ & 90.8 & $6,598,137$ & 90.8 & $6,263,855$ & 86.2 & $6,263,855$ & 86.2 & $6,624,789$ & 91.1 & $6,624,401$ & 91.1 \\
\hline NHPI alone & 146,565 & 57.6 & 143,683 & 56.5 & 138,968 & 54.6 & 136,442 & 53.6 & 144,115 & 56.7 & 144,049 & 56.6 \\
\hline $\begin{array}{l}\text { SOR alone } \\
\text { Two or More }\end{array}$ & $2,656,812$ & 49.4 & $2,656,812$ & 49.4 & 2,592,965 & 48.2 & $2,592,965$ & 48.2 & $2,627,712$ & 48.8 & $2,626,585$ & 48.8 \\
\hline Races & $1,367,434$ & 28.6 & $1,450,139$ & 30.4 & $1,272,013$ & 26.6 & $1,329,544$ & 27.8 & $1,440,223$ & 30.2 & $1,385,900$ & 29.0 \\
\hline
\end{tabular}

\begin{tabular}{|c|c|c|c|c|}
\hline \multirow{2}{*}{$\begin{array}{l}\text { Hispanic Origin } \\
\text { Responses }\end{array}$} & \multicolumn{2}{|c|}{ Method 1} & \multicolumn{2}{|c|}{ Method 2} \\
\hline & Number & Percent & Number & Percent \\
\hline Hispanic & $6,464,839$ & 92.1 & $6,332,126$ & 90.2 \\
\hline Non-Hispanic & $31,323,085$ & 96.2 & $31,945,255$ & 98.1 \\
\hline
\end{tabular}


Table 5. Percentage of ARTPD Race Data Matched to the 2010 Census Nonresponse Follow-up Universe

\begin{tabular}{|c|c|c|c|c|c|c|c|c|c|c|c|c|}
\hline \multirow{2}{*}{$\begin{array}{l}\text { Race } \\
\text { Responses } \\
\end{array}$} & \multicolumn{2}{|c|}{ Method 1} & \multicolumn{2}{|c|}{ Method 2} & \multicolumn{2}{|c|}{ Method 3} & \multicolumn{2}{|c|}{ Method 4} & \multicolumn{2}{|c|}{ Method 5} & \multicolumn{2}{|c|}{ Method 6} \\
\hline & Number & Percent & Number & Percent & Number & Percent & Number & Percent & Number & Percent & Number & Percent \\
\hline White alone & $22,936,984$ & 95.1 & $22,936,984$ & 95.1 & $23,042,634$ & 95.6 & $23,042,634$ & 95.6 & $23,044,543$ & 95.6 & $23,028,484$ & 95.5 \\
\hline Black alone & $5,866,751$ & 95.9 & $5,866,751$ & 95.9 & $5,894,498$ & 96.3 & $5,894,498$ & 96.3 & $5,871,854$ & 96.0 & $5,870,943$ & 96.0 \\
\hline AIAN alone & 276,290 & 67.3 & 259,183 & 63.1 & 266,200 & 64.8 & 256,677 & 62.5 & 246,818 & 60.1 & 269,715 & 65.7 \\
\hline Asian alone & 897,607 & 85.5 & 897,607 & 85.5 & 874,058 & 83.2 & 874,058 & 83.2 & 902,504 & 86.0 & 902,414 & 85.9 \\
\hline NHPI alone & 41,083 & 57.0 & 40,119 & 55.6 & 39,997 & 55.5 & 39,156 & 54.3 & 40,256 & 55.8 & 40,226 & 55.8 \\
\hline $\begin{array}{l}\text { SOR alone } \\
\text { Two or More }\end{array}$ & 851,696 & 45.0 & 851,696 & 45.0 & 835,727 & 44.1 & 835,727 & 44.1 & 841,699 & 44.4 & 841,149 & 44.4 \\
\hline Races & 253,700 & 21.2 & 272,659 & 22.8 & 238,491 & 19.9 & 251,749 & 21.0 & 269,287 & 22.5 & 257,051 & 21.5 \\
\hline
\end{tabular}

\begin{tabular}{|c|c|c|c|c|}
\hline & \multicolumn{2}{|c|}{ Hispanic Origin } & \multicolumn{2}{|l|}{ Race } \\
\hline & Number & Percent & Number & Percent \\
\hline Total & $251,320,952$ & 100.0 & $253,905,696$ & 100.0 \\
\hline Matching & $217,393,894$ & 86.5 & $198,805,047$ & 78.3 \\
\hline Non-Matching & $8,068,227$ & 3.2 & $11,707,695$ & 4.6 \\
\hline Missing ARTPD Data & $25,858,831$ & 10.3 & 43,392,954 & 17.1 \\
\hline \multicolumn{5}{|c|}{ Source: 2010 Census and ARTPD } \\
\hline Note $\cdot$ ARTPD $=$ Ad & Records al & ind Dout & & \\
\hline
\end{tabular}


Table 7. Multinomial Logistic Regression Results, Odds Ratios

\begin{tabular}{|c|c|c|c|c|}
\hline \multirow[b]{2}{*}{ Variables } & \multicolumn{2}{|c|}{$\begin{array}{l}\text { Model 1: Hispanic Origin } \\
\text { (Matching Hispanic origin } \\
\text { is the reference) }\end{array}$} & \multicolumn{2}{|c|}{$\begin{array}{l}\text { Model 2: Race } \\
\text { (Matching race } \\
\text { is the reference) }\end{array}$} \\
\hline & $\begin{array}{c}\text { Non- } \\
\text { matching } \\
\text { responses }\end{array}$ & $\begin{array}{l}\text { Missing in } \\
\text { ARTPD }\end{array}$ & $\begin{array}{c}\text { Non- } \\
\text { matching } \\
\text { responses }\end{array}$ & $\begin{array}{l}\text { Missing in } \\
\text { ARTPD }\end{array}$ \\
\hline \multicolumn{5}{|l|}{ Ethnicity/Race in Census (Non-Hispanic White alone omitted) } \\
\hline Hispanic & $1.58^{* * *}$ & $0.71^{* * *}$ & $42.64^{* * *}$ & $11.24^{* * *}$ \\
\hline Non-Hispanic Black alone & $0.67 * * *$ & $0.88 * * *$ & $1.63^{* * *}$ & $0.71^{* * *}$ \\
\hline Non-Hispanic American Indian or Alaska Native alone & $2.20 * * *$ & $0.89 * * *$ & $13.67 * * *$ & $0.41^{* * *}$ \\
\hline Non-Hispanic Asian alone & $2.51^{* * *}$ & $2.98 * * *$ & $6.29 * * *$ & $10.88 * * *$ \\
\hline Non-Hispanic Native Hawaiian or Pacific Islander alone & $3.60^{* * *}$ & $2.01^{* * *}$ & $35.95 * * *$ & $9.24 * * *$ \\
\hline \multicolumn{5}{|l|}{ Age (18-44 years old omitted) } \\
\hline $0-17$ years old & $1.24^{* * *}$ & $12.66^{* * *}$ & $2.19 * * *$ & $16.85^{* * *}$ \\
\hline 45-64 years old & $0.96^{* * *}$ & $0.40^{* * *}$ & $0.95^{* * *}$ & $0.48^{* * *}$ \\
\hline 65 years and older & $0.83^{* * *}$ & $0.24^{* * *}$ & $0.86^{* * *}$ & $0.25 * * *$ \\
\hline \multicolumn{5}{|l|}{ Gender (Female omitted) } \\
\hline Male & $0.74^{* * *}$ & $1.07^{* * *}$ & $1.05^{* * *}$ & $1.00^{* * *}$ \\
\hline \multicolumn{5}{|l|}{ Household Tenure (Owner omitted) } \\
\hline Renter & $1.08 * * *$ & $1.04^{* * *}$ & $1.16^{* * *}$ & $1.63^{* * *}$ \\
\hline No rent paid & $1.09 * * *$ & $1.08 * * *$ & $1.09 * * *$ & $1.48^{* * *}$ \\
\hline \multicolumn{5}{|l|}{ Household Type (Married couple family omitted) } \\
\hline Single father family & $1.12^{* * *}$ & $0.61^{* * *}$ & $1.07 * * *$ & $0.96^{* * *}$ \\
\hline Single mother family & $1.18^{* * *}$ & $0.43^{* * *}$ & $1.02^{* * *}$ & $0.58^{* * *}$ \\
\hline Other household type & $1.06^{* * *}$ & $0.97^{* * *}$ & $1.13^{* * *}$ & $1.02 * * *$ \\
\hline \multicolumn{5}{|l|}{ Household Size (1 person omitted) } \\
\hline 2 persons & $1.06 * * *$ & $1.04 * * *$ & $1.03^{* * *}$ & $1.42^{* * *}$ \\
\hline 3 persons & $1.13^{* * *}$ & $1.32 * * *$ & $1.10^{* * *}$ & $2.22 * * *$ \\
\hline 4 persons & $1.11^{* * *}$ & $1.30^{* * *}$ & $1.10^{* * *}$ & $2.42 * * *$ \\
\hline 5 or more persons & $1.07^{* * *}$ & $1.07^{* * *}$ & $1.18^{* * *}$ & $2.64 * * *$ \\
\hline \multicolumn{5}{|l|}{ Census Mode (Mailout/Mailback omitted) } \\
\hline Nonresponse follow-up & $1.23^{* * *}$ & $1.13^{* * *}$ & $1.48^{* * *}$ & $1.27^{* * *}$ \\
\hline Other mode & $1.06^{* * *}$ & $1.02 * * *$ & $1.06^{* * *}$ & $1.23 * * *$ \\
\hline \multicolumn{5}{|l|}{ Region (West omitted) } \\
\hline Midwest & $0.63^{* * *}$ & $0.84^{* * *}$ & $0.77 * * *$ & $1.03^{* * *}$ \\
\hline South & $0.76^{* * *}$ & $0.99 * * *$ & $0.77 * * *$ & $1.07 * * *$ \\
\hline Northeast & $0.97^{* * *}$ & $0.94^{* * *}$ & $0.94^{* * *}$ & $1.09 * * *$ \\
\hline \multicolumn{5}{|l|}{ Address Type (Urban omitted) } \\
\hline Rural & $0.76^{* * *}$ & $0.93 * * *$ & $0.85^{* * *}$ & $0.93^{* * *}$ \\
\hline Percent non-Hispanic White in tract & $0.99^{* * *}$ & $1.00^{* * *}$ & $1.00^{* * *}$ & $1.00^{* * *}$ \\
\hline Median household income in tract (log) & $1.39 * * *$ & $2.06^{* * *}$ & 1.00 & $1.19 * * *$ \\
\hline Unweighted N & 251, & ,952 & 253 & 696 \\
\hline $\begin{array}{l}{ }^{* * *} \mathrm{p}<.001 \\
\text { Source: } 2010 \text { Census and ARTPD } \\
\text { Note: ARTPD = Administrative Records and Third Party }\end{array}$ & & & & \\
\hline
\end{tabular}


Table 8. Distribution of Dependent Variables used in Multinomial Logistic

Regression Models - 2010 Census Nonresponse Follow-up Universe

\begin{tabular}{|l|rr|rr|}
\hline & \multicolumn{2}{|c|}{ Hispanic Origin } & \multicolumn{2}{c|}{ Race } \\
& Number & Percent & \multicolumn{1}{c|}{ Number } & Percent \\
\hline Total & $43,749,283$ & 100.0 & $43,761,931$ & 100.0 \\
Matching & $36,869,732$ & 84.3 & $31,020,527$ & 70.9 \\
Non-Matching & $1,706,885$ & 3.9 & $2,996,525$ & 6.8 \\
Missing ARTPD Data & $5,172,666$ & 11.8 & $9,744,879$ & 22.3 \\
\hline Source: 2010 Census and ARTPD \\
Note: ARTPD = Administrative Records and Third Party Data \\
\hline
\end{tabular}


Table 9. Multinomial Logistic Regression Results, Odds Ratios - 2010 Census Nonresponse Follow-up Universe

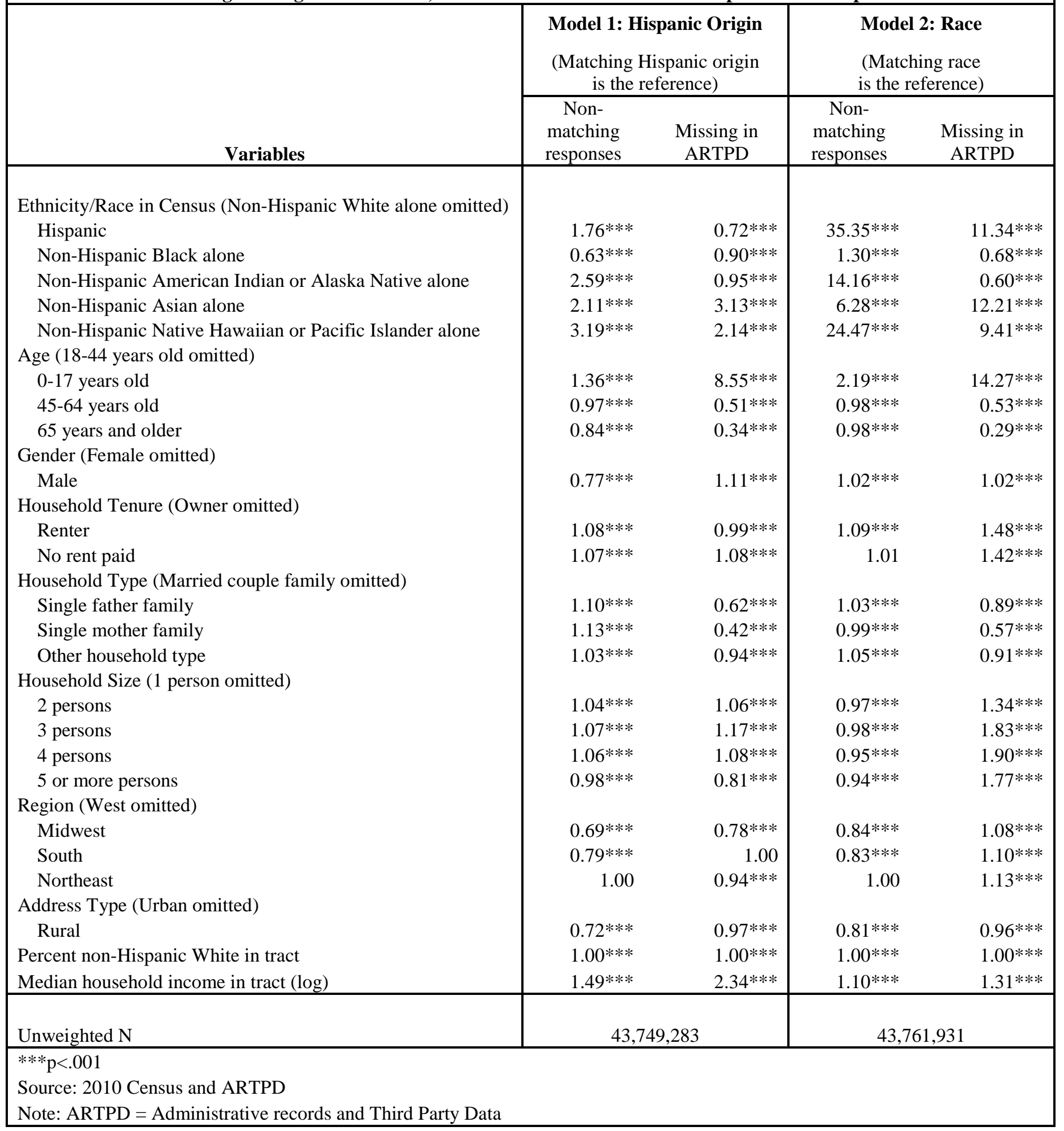

